\title{
Bioinspired green synthesis of copper oxide nanoparticles from Syzygium alternifolium (Wt.) Walp: characterization and evaluation of its synergistic antimicrobial and anticancer activity
}

\author{
Pulicherla Yugandhar ${ }^{1} \cdot$ Thirumalanadhuni Vasavi $^{2} \cdot$ Palempalli Uma Maheswari Devi $^{2}$ • \\ Nataru Savithramma ${ }^{1}$
}

Received: 16 June 2017 / Accepted: 17 August 2017/Published online: 23 August 2017

(c) The Author(s) 2017. This article is an open access publication

\begin{abstract}
In recent times, nanoparticles are attributed to green nanotechnology methods to know the synergistic biological activities. To accomplish this phenomenon, present study was aimed to synthesize copper oxide nanoparticles (CuO NPs) by using Syzygium alternifolium stem bark, characterized those NPs using expository tools and to elucidate high prioritized antimicrobial and anticancer activities. Synthesized particles exhibited a color change pattern upon synthesis and affirmed its respective broad peak at $285 \mathrm{~nm}$ which was analyzed through UV-vis spectroscopy. FT-IR study confirmed that phenols and primary amines were mainly involved in capping and stabilization of nanoparticles. DLS and Zeta potential studies revealed narrow size of particles with greater stability. XRD studies revealed the crystallographic nature of particles with $17.2 \mathrm{~nm}$ average size. Microscopic analysis by using TEM revealed that particle size range from 5-13 nm and most of them were spherical in shape, non-agglomerated and poly-dispersed in condition. Antimicrobial studies of particles showed highest inhibitory activity against $E$. coli and $T$. harzianum among bacterial and fungal strains, respectively. The scope of this study is extended by examining anticancer activity of $\mathrm{CuO}$ NPs. This study exhibited potential anticancer activity towards MDA-MB231 human breast cancer lines. Overall, these examinations relate that the S. alternifolium is described as efficient wellbeing plant and probabilistically for the design and
\end{abstract}

Pulicherla Yugandhar

yugandharbotany@gmail.com

1 Department of Botany, Sri Venkateswara University, Tirupati, AP 517502, India

2 Department of Applied Microbiology, Sri Padmavati Mahila Visvavidyalayam, Tirupati, AP 517502, India synthesis of nanoparticles for human health. This study paves a way to better understand antimicrobial and anticancer therapeutic drug potentials of nanoparticles to design and analysis of pharmaceuticals by in vivo and in vitro approaches.

Keywords Syzygium alternifolium - Stem bark · CuO NPs - Characterization - Antimicrobial activity - Anticancer activity

\section{Introduction}

In the present century research on nanotechnology gains much importance in the fields of biology, medicine, physics, chemistry and electronics. When coming to the biology nanoparticles are synthesized with the help of medicinal plants as reducing agents and is a fascinating research area by synthesizing different types of nanoparticles like, calcium, copper, gold, iron, silver and zinc (Kumar et al. 2016). Among these, copper nanoparticles have enormous considerations in the preparation of algaecides, fungicides, antifouling and antimicrobial agents. Thereafter which attract attention in various fields due to its catalytic, electric, optical, photonic and superconducting properties (Padil and Cernik 2013). The green synthesis method of CuO NPs with medicinal plants is eco-friendly, cost effective and stable. However, the research going on with this method is very seldom. Whereas the chemical- and physical-mediated methods were very familiar, but they arise some difficulties to humans as well as to the environment. In chemical-mediated synthesis, the copper salts were reduced with the help of reducing agents like, sodium borohydride, hydrazine, microemulsions and with evaporation/condensation methods. The use of sodium borohydride can irritate skin, eyes, 
nose and throat while exposure. Higher exposures may cause pulmonary edema and affect the nervous system (Yugandhar et al. 2015). Hydrazine is a colorless, flammable inorganic compound, exposure to this chemical cause irritation of eyes, nose and throat. Higher exposures may lead to seizure, coma, kidney and liver damages. The disadvantage of microemulsion was its high expensive cost, which may adsorb on the surface of particles, separation and removal of them from final products was difficult, which ultimately reduces the usability of nanoparticles (Capek 2004). The evaporation/condensation method occupies large space, consumes more power and the obtained powders were in highly agglomerated state. These nano-powders were treated with high purity gas streams to cause compositional and structural modifications of nanoparticles, which arises hazardous waste materials to the environment (Tavakoli et al. 2007).

Coming to the physical-mediated familiar methods, the pulse laser ablation, microwave-assisted and pulsed/explosion wire discharge methods are in trend. The disadvantage of the laser ablation method was its high cost, high energy consumption and low product efficiency (Kalyanaraman et al. 1998). The microwave-assisted synthesis has radiation health hazards and the cost of microwave systems. The pulsed/explosion wire discharge method was not cost effective, limited production efficiency and contaminations of the final product were considered as limitations to this method (Umer et al. 2012). With these constraints, medicinal plants are employed for the alternative and future strategies to synthesize nanoparticles. These medicinal plants are acting as eco-friendly, safety, cost effective and green reducing sources for synthesis of copper nanoparticles. In recent past, the $\mathrm{CuO}$ NPs were synthesized from Acalypha indica (Sivaraj et al. 2014), Aloe vera (Vijay Kumar et al. 2015) and Punica granatum (Ghidana et al. 2016). These nanoparticles exhibit different biological activities like, anticancer (Sankar et al. 2014), anti-inflammatory, mosquito larvicidal (Angajala et al. 2014), wound healing (Tiwari et al. 2014), antimicrobial (Shende et al. 2015), anti diabetic and antioxidant activity (Ghosh et al. 2015). However, there is no report on green synthesis of $\mathrm{CuO}$ NPs from $S$. alternifolium and there is no validation of antimicrobial activity against microorganisms and anticancer activity against MDA-MB-231 breast cancer cell lines. Hence, the present work has been undertaken to synthesize $\mathrm{CuO} \mathrm{NPs}$ and to study their synergistic antimicrobial and anticancer activities.

The plant $S$. alternifolium was grown on top hills of Tirumala forest, Chittoor District, Andhra Pradesh, India. It belongs to the family Myrtaceae and is locally known as mogi or adavinerudu. This is a medium sized perennial tree and has importance in both commercial and medicinal practices. The plant was exploited in a commercial way for constructing buildings in the local premises. Fruit part of the plant was eaten as an edible fruit, cooked to make into squashes, jellies and local vinegar by the tribal people. Besides to these commercial purposes, the local people of Tirumala hills practiced to cure stomach ulcers by oral administration of fruit juice, external application of fruit pulp for rheumatic pains. Chenchu and Nakkala tribes of Tirumala hills were traditionally practiced to cure diarrhea by using fruit powder (Savithramma et al. 2014a). Yanadi tribe and local villagers of Veyilingalakona Sacred Grove utilized fruit powder to control diabetes (Savithramma et al. 2014b). The oral administration of stem bark decoction regulates the blood sugar levels and reduces intestinal ulcers (Sudhakar et al. 2012). Due to the exploited collection of plant parts for commercial as well as medicinal purposes and other biotic/abiotic baroreceptor factors, this plant was categorized under endemic and endangered species to these hills by "The IUCN Red List of Threatened Species" (Saha et al. 2015).

\section{Materials and methods}

\section{Collection of plant material}

Fresh part of S. alternifolium stem bark was collected from Nagatheertham area of Tirumala hills, Chittoor District, Andhra Pradesh, India. Stem bark was washed thrice with running tap water followed by Milli Pak pure water. They may dry up to 15-20 days under shady conditions to evaporate residual moisture and finally ground with blender for further use.

\section{Chemicals}

Deionized Milli Q water (Merck Water Solutions, France), $\mathrm{CuSO}_{4} \cdot 5 \mathrm{H}_{2} \mathrm{O}$ (Sisco Research Laboratories Pvt. Ltd., India), $\mathrm{NaOH}, 3$-(4,5-dimethylthiazol-2-Yl)-2,5-diphenyltetrazolium bromide (MTT), Nutrient broth agar and Potato dextrose agar media (Sigma Aldrich, Bangalore, India), Fluconazole, Streptomycin and Doxorubicin (Thermo Fisher Scientifics, India) were mainly used in this work.

\section{Synthesis of nanoparticles}

$5 \mathrm{~g}$ of finely grounded plant powder was extracted with $100 \mathrm{ml}$ of Milli Q water on boiling water bath for $30 \mathrm{~min}$ and were filtered with Whatmann no. 1 filter paper. An aliquot of $10 \mathrm{ml}$ of aqueous plant extract was titrated with $100 \mathrm{ml}$ of $5 \mathrm{mM} \mathrm{CuSO}_{4} \cdot 5 \mathrm{H}_{2} \mathrm{O}$ for reduction of $\mathrm{CuO}$ NPs at $50{ }^{\circ} \mathrm{C}$ for $2 \mathrm{~h}$. Obtained mixture was centrifuged at 10,000 RPM for $15 \mathrm{~min}$ to separate agglomerated, broad sized particles as well as plant admixtures. 


\section{Characterization}

The green synthesized nanoparticles were characterized by using different spectroscopic and microscopic tools. Initial confirmation of nanoparticles was done by UV-vis spectroscopy (Spectro UV 2080, Analytical Technologies, India) to know which of the metal nanoparticles were actually reduced and which of the phytochemicals were actually involved in reduction of nanoparticles by surface plasmon resonance method. To comprehend which of the phytochemicals were actually involved in capping and stabilization of nanoparticles, the FTIR spectroscopy (ALPHA interferometer, ECO-ATR, Bruker, Ettlingen, Karlsruhe, Germany) was utilized. Dynamic light scattering (DLS) and Zeta potential of synthesized nanoparticles were analyzed to know the average size and stability of particles (Nanopartica analyzer, Horiba SZ 100, Japan). XRD (Shimadzu, XRD-6000) was used to analyze crystalline nature and calculate the average size of particles. Microscopic analysis with TEM (HF-3300, $300 \mathrm{kV}$ TEM/ STEM, Hitachi) instrument reveals the size, shape, dispersed nature and agglomerated pattern of nanoparticles. Along with these, the publicly accessed software tools like Image $\mathrm{J}$ and CrysTBox were used to know the average size and diffraction pattern of nanoparticles.

\section{Antimicrobial activity}

The antimicrobial activity of green synthesized nanoparticles was carried out against seven selected bacterial strains include Bacillus subtilis ATCC 6633, Staphylococcus aureus ATCC 6538, Escherichia coli ATCC 25922, Klebsiella pneumonia ATCC 43816, Proteus vulgaris ATCC 13315, Pseudomonas aeruginosa ATCC 15442, Salmonella typhimurium ATCC 14028 and five fungal strains include Alternaria solani ATCC 32904, Aspergillus flavus ATCC 9643, Aspergillus niger ATCC 16404, Penicillium chrysogenum ATCC 11709 and Trichoderma harzianum ATCC 20476 by using disc diffusion assay method (Cruickshank 1986). To know the minimum inhibitory concentration of prepared nanoparticles, serial concentrations of 5, 10, 20, 40 and $80 \mu \mathrm{g} / \mathrm{ml}$ were tested. Finally, found that $20 \mu \mathrm{g} / \mathrm{ml}$ concentrations showed minimum growth inhibition and $80 \mu \mathrm{g} / \mathrm{ml}$ concentrations as almost lethal toxic to all the microorganisms. For this, $40 \mu \mathrm{g} / \mathrm{ml}$ concentrations were used as $\mathrm{LD}_{50}$ value for antimicrobial activity of prepared nanoaprticles. The plant extract $(1 \mathrm{mg} /$ $\mathrm{ml})$ and $\mathrm{CuSO}_{4} \cdot 5 \mathrm{H}_{2} \mathrm{O}(5 \mathrm{mM})$ was used as positive and negative controls, respectively. Streptomycin and Fluconazole $(10 \mu \mathrm{g} / \mathrm{ml} / \mathrm{disc})$ were used as standard controls for bacterial and fungal strains, respectively. An aliquot of $20 \mu \mathrm{l}$ per disc was prepared for above-mentioned aliquots and an amount of $50 \mu \mathrm{l}$ per petri plate microbial broth cultures were used for swabbing on culture medium. The triplicates of all these experiments were carried out under sterile conditions and were incubated at $37{ }^{\circ} \mathrm{C}$ for $24-48 \mathrm{~h}$.

\section{Anticancer activity}

MDA-MB-231 Human breast cancer cell lines were procured from National Centre for Cell Science, Pune, India. The $0.2 \mathrm{ml}$ of Dulbecco's Modified Eagle's Medium was used to growing up $1 \times 10^{4}$ cells per well in 96-well plate. These cell lines were incubated in $5 \% \mathrm{CO}_{2}$ atmosphere at $37{ }^{\circ} \mathrm{C}$ for $24 \mathrm{~h}$ supplemented with $2 \mathrm{mM} / \mathrm{l}$ glutamine, $10 \%$ Foetal Bovine Serum (FBS) with $10 \mu \mathrm{g} / \mathrm{ml}$ of ciprofloxacin (Jagadeesh et al. 2013). After that medium was expelled and refilled with $0.15 \mathrm{ml}$ of $10,25,50$ and $100 \mu \mathrm{g} / \mathrm{ml}$ concentrations of $\mathrm{CuO}$ NPs. The $0.1 \%$ of DMSO was prepared for dissolving sample nanoparticles as well as MTT dye crystals has been set as negative control and $1 \mu \mathrm{M}$ doxorubicin treated cell lines were set as positive control. The initial experiment was maintained from 0 to $72 \mathrm{~h}$ of timeline period with $12 \mathrm{~h}$ of time gap period to check probability of cell toxicity. It provides specific time course period to allow functional cell mortality to understand the experiment in a flexible and adaptable way. According to that, less cell toxicity was observed at 12-, 24-, 36-h period and greater cell toxicity was observed at 60 - and 72 -h period. It reduces the chance of taking readings with ELISA reader. The $48 \mathrm{~h}$ of time period showed optimum reliability than other timeline periods. Due to this, the $48 \mathrm{~h}$ of incubation period was considered for nanoparticles cytotoxicity prediction analysis. Triplicates of experiments were carried out and incubated them up to $48 \mathrm{~h}$ at $37^{\circ} \mathrm{C}$. Further, at the end of incubation period the sample solutions were discarded and incubated for $4 \mathrm{~h}$ at $37{ }^{\circ} \mathrm{C}$ by adding $0.02 \mathrm{ml}$ of MTT reagent $(5 \mathrm{mg} / \mathrm{ml})$ to each well. After that, MTT containing medium was discarded and refilled with $0.15 \mathrm{ml} /$ well DMSO to dissolve formazan crystals. The viability of cell lines was read at $570 \mathrm{~nm}$ by an ELISA reader. The percentage of cell viability was calculated by the following formula (Kadirareddy et al. 2016):

Percentage of cell viability $=\frac{\text { OD value of treated cell lines }}{\text { OD value of negative control }}$ $\times 100$.

\section{Results and discussion}

\section{UV-vis spectroscopy}

In green synthesis protocols, the matter of first importance is the visual characterization of the color change pattern upon synthesis of nanoparticles. Here, observed that stem 
bark-mediated $\mathrm{CuO}$ NPs manifest a color change from brown to thick brown (Fig. 1). The color change mechanism of the reaction mixture is due to a reaction between copper(II) sulfate pentahydrate and sodium hydroxide to form copper(II) hydroxide (2), which reacts with the plant ascorbic acid to give dehydroascorbic acid and copper(I) oxide (3).

$$
\begin{aligned}
& \mathrm{CuSO}_{4} \cdot 5 \mathrm{H}_{2} \mathrm{O}+2 \mathrm{NaOH} \rightarrow \mathrm{Na}_{2} \mathrm{SO}_{4} \\
&+\mathrm{Cu}(\mathrm{OH})_{2}+5 \mathrm{H}_{2} \mathrm{O}, \\
& 2 \mathrm{Cu}(\mathrm{OH})_{2}+\mathrm{C}_{6} \mathrm{H}_{8} \mathrm{O}_{6} \rightarrow \mathrm{Cu}_{2} \mathrm{O}+\mathrm{C}_{6} \mathrm{H}_{6} \mathrm{O}_{6}+3 \mathrm{H}_{2} \mathrm{O} .
\end{aligned}
$$

When the reaction time was increased, the copper(I) oxide was formed to $\mathrm{CuO}$ nanoparticles by a series of reactions (4-6).

$$
\begin{aligned}
& \mathrm{Cu}_{2} \mathrm{O}+\mathrm{OH}^{-}+\mathrm{H}_{2} \mathrm{O} \rightarrow\left[\mathrm{Cu}(\mathrm{OH})_{2}\right]^{-}+\mathrm{CuOH}, \\
& 2 \mathrm{CuOH} \rightarrow \mathrm{Cu}_{2} \mathrm{O}+\mathrm{H}_{2} \mathrm{O}, \\
& 4 \mathrm{CuOH}+\mathrm{O}_{2} \rightarrow 4 \mathrm{CuO}+2 \mathrm{H}_{2} \mathrm{O} .
\end{aligned}
$$

After the reduction of $\mathrm{CuO}$ material, they formed as spherical shaped $\mathrm{CuO}$ nanoparticles by the action of plant phytochemicals. Plant phytochemicals act as capping and stabilizing agents to give particular shape and to avoid agglomeration between the particles (Baoshun et al. 2016). When analyzed these samples with UV-vis spectrophotometer between the scan range of 190-750 nm. Nanoparticles in the reaction mixture were excited by absorbing light at different wavelengths due to surface plasmon resonance (SPR) nature to give respective broad peak, represents which metal nanoparticles was actually reduced. Synthesized reaction mixture showed that a broad peak at $285 \mathrm{~nm}$ corresponds to copper oxide, which

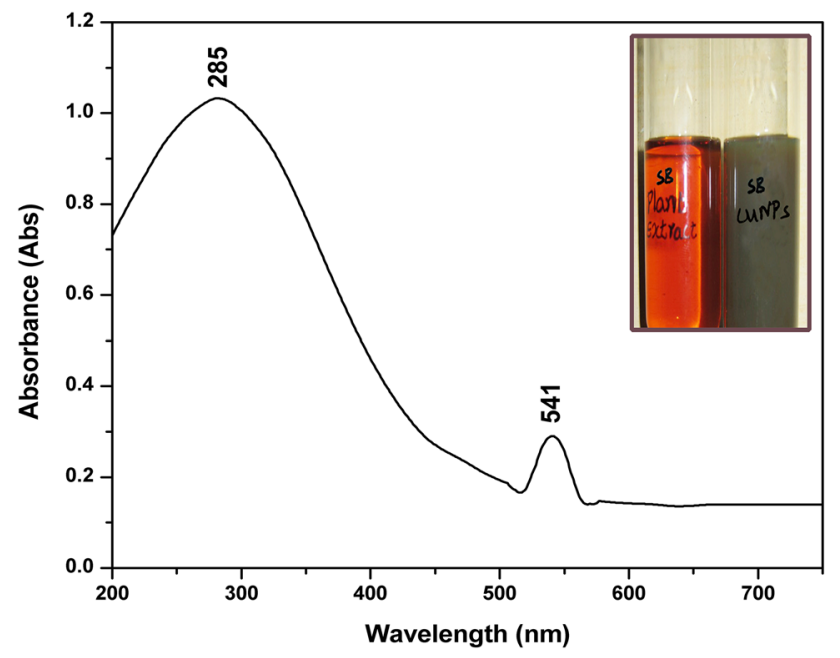

Fig. 1 UV-vis spectroscopic analysis of synthesized $\mathrm{CuO}$ NPs represents two peaks correspond to copper oxide and ascorbic acid. Inset photograph represents color change pattern upon synthesis confirms the synthesized nanoparticles were $\mathrm{CuO}$ NPs. Another small peak obtained at $541 \mathrm{~nm}$ confirmed as ascorbic acid, acts as reducing agent for CuO NPs (Fig. 1). Similar type of result was observed from copper nanoparticles synthesized with the help of Punica granatum peel extract (Ghidana et al. 2016).

\section{FT-IR analysis}

FT-IR study of biologically synthesized nanoparticles was analyzed within the scan range of $4000-500 \mathrm{~cm}^{-1}$ to know the feasible phytochemicals responsible for capping and stabilization. Here, synthesized nanoparticles exhibit broad peaks at $3313 \mathrm{~cm}^{-1}$ corresponds to $\mathrm{O}-\mathrm{H}$ bond of phenols and $1640 \mathrm{~cm}^{-1}$ corresponds to $\mathrm{C}=\mathrm{O}$ stretching vibration of primary amines. Thus, consequences confirmed that phenols and primary amines of plant extracts were mainly responsible for capping and stabilization of $\mathrm{CuO}$ NPs (Fig. 2). These kind of results was obtained from copper nanoparticles synthesized with the help of Commelina nudiflora whole plant extract (Kuppusamy et al. 2017).

\section{Zeta potential and particle size determination}

Synthesized nanoparticles were dispersed in $10 \mathrm{ml}$ of distilled water to know the particle size with DLS by surpassing laser scattering light and set instrumental conditions like, $0.892 \mathrm{mPa} \mathrm{s}$ of dispersion medium viscosity, $173^{\circ}$ of scattering angle, $25.2^{\circ} \mathrm{C}$ of temperature. Whereas to know the zeta potential by adding few $\mu$ l of dispersed nanoparticle solution to electrode and set the conditions like, $0.264 \mathrm{mS} / \mathrm{cm}$ of conductivity, $3.3 \mathrm{~V}$ of electrode voltage, $25.2{ }^{\circ} \mathrm{C}$ of temperature and the data acquisition time was set to $1 \mathrm{~min}$. Synthesized

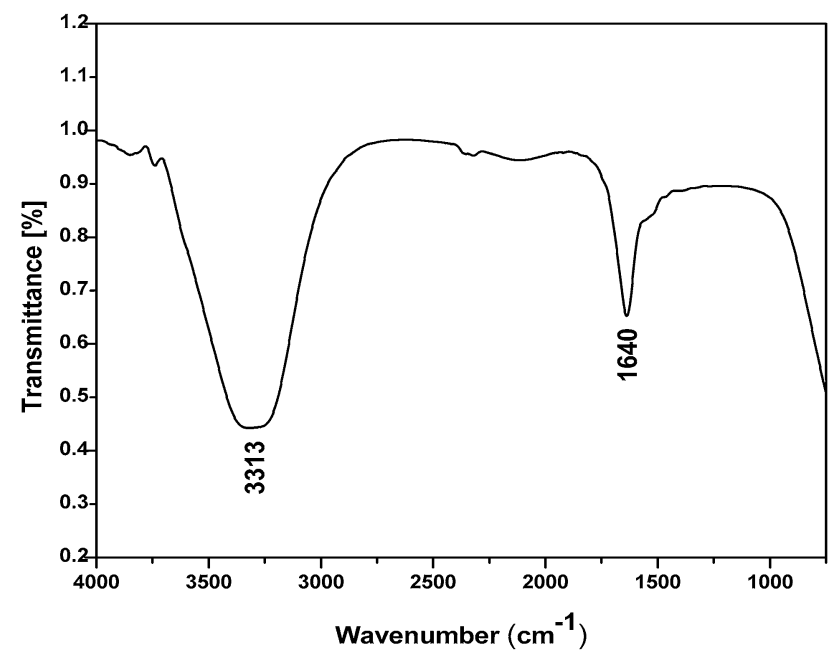

Fig. 2 FT-IR analysis of synthesized CuO NPs represents two broad peaks correspond to phenols and primary amines 
nanoparticles exhibited polydispersed type of particles with $2.6 \mathrm{~nm}$ average size and $-63.9 \mathrm{mV}$ of zeta potential value (Fig. 3). These outcomes indicated that the plant $S$. alternifolium was a good source for reduction of narrow size of $\mathrm{CuO}$ NPs. The higher negative zeta potential value confirmed repulsion between particles to thwart agglomeration. This indicates synthesized nanoparticles have higher stability in a liquid medium.

\section{XRD analysis}

XRD analysis of synthesized nanoparticles showed 08 Bragg reflections at $2 \theta$ of $X$-axis at $32.4^{\circ}, 35.6^{\circ}, 38.8^{\circ}$, $48.9^{\circ}, 53.3^{\circ}, 58.2^{\circ}, 61.6^{\circ}, 66.3^{\circ}$ corresponds to 110,111 , 200, -202, 020, 202, -113 and 022 integer 'hkl' planes, respectively (Fig. 4). This indicates end-centered monoclinic crystalline nature of nanoparticles. This result was affirmed by cross checking the obtained data with International centre for diffraction data (ICDD) file no. 801916. This type of results was obtained from an A. vera leaf extract mediated CuO NPs (Vijay Kumar et al. 2015). Highest Bragg reflection was obtained at $2 \theta$ of $38.8^{\circ}$ to predict full width half maximum (FWHM) value, i.e., 5 and was calculated to $17.2 \mathrm{~nm}$ average size of the particle by using the following Debye-Scherrer equation:

$D=\frac{k \lambda}{\beta \cos \theta}$.

\section{TEM analysis}

An ample resolution up to $2 \mathrm{~nm}$ is possible by high resolution transmission electron microscope (HR-TEM) analysis. Because, focusing of $300 \mathrm{kV}$ of electron beam energy

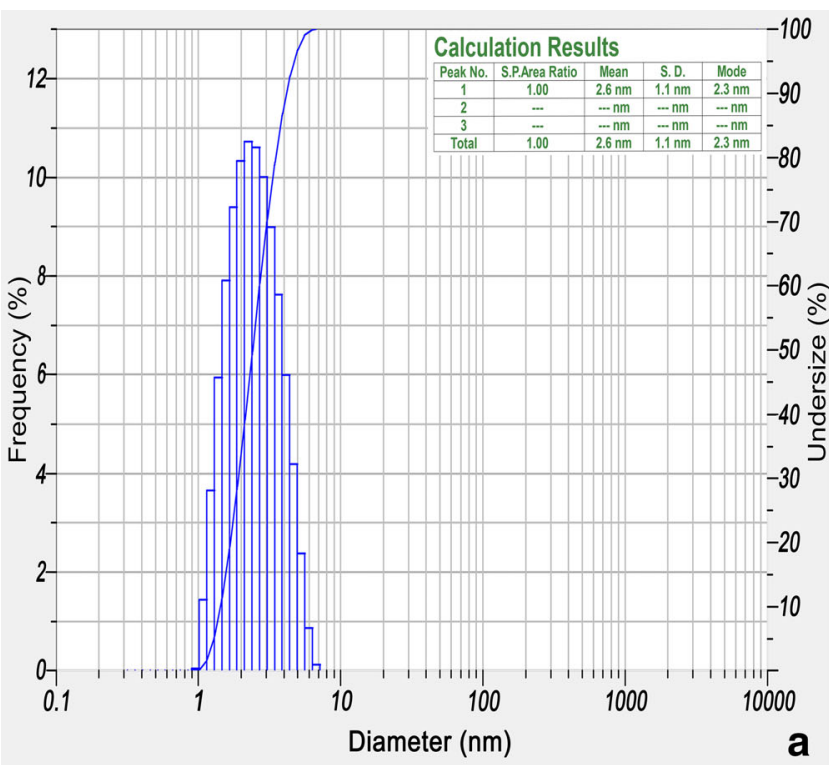

Fig. 3 a DLS, b Zeta potential analysis of synthesized CuO NPs is possible on nanoparticles. The $20 \mathrm{~nm}$ resolution studies with TEM analysis revealed that the particles were spherical in shape, non-agglomerated, polydispersed with the size range from 5 to $13 \mathrm{~nm}$ (Fig. 5b). The $2 \mathrm{~nm}$ resolution studies of nanoparticles showed $0.28 \mathrm{~nm}$ size of ' $d$ ' space. This result indicates the synthesized nanoparticles were crystalline in nature (Fig. 5c).

\section{Particle analysis}

The synthesized nanoparticles were analyzed by different image processing software tools like ImageJ and CrysTBox. ImageJ (image processing and analysis in Java) is one of the public domain Java empowered programs widely

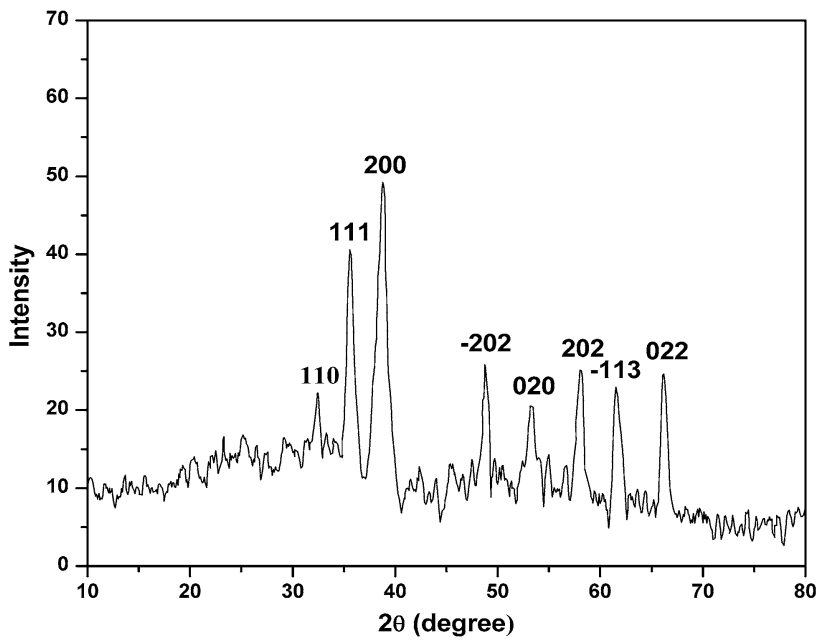

Fig. 4 XRD analysis of synthesized CuO NPs represents eight Bragg reflections corresponding to end-centered monoclinic crystalline nature of nanoparticles

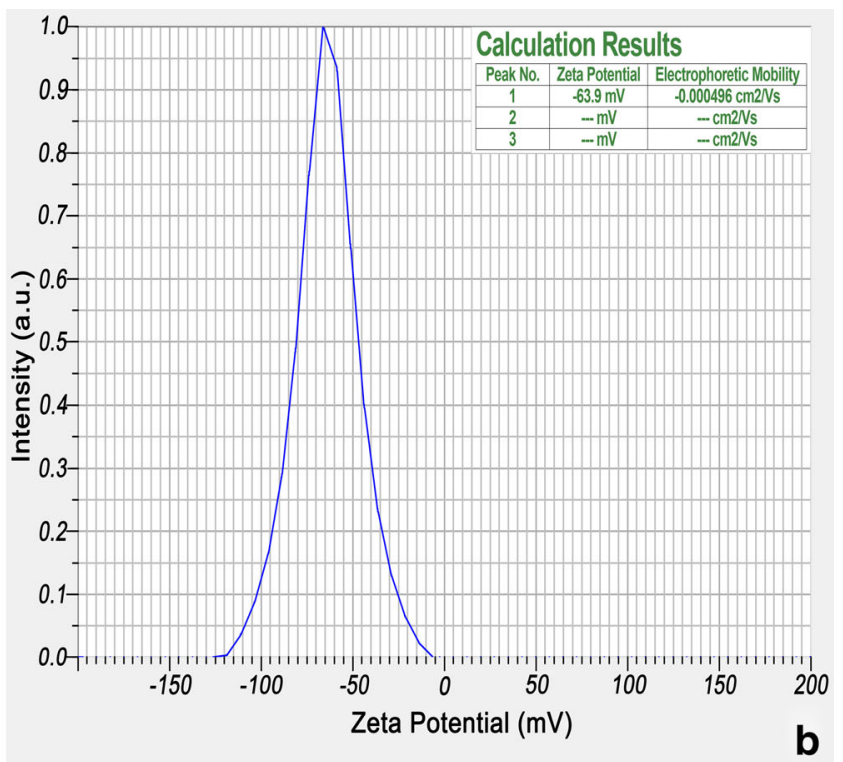



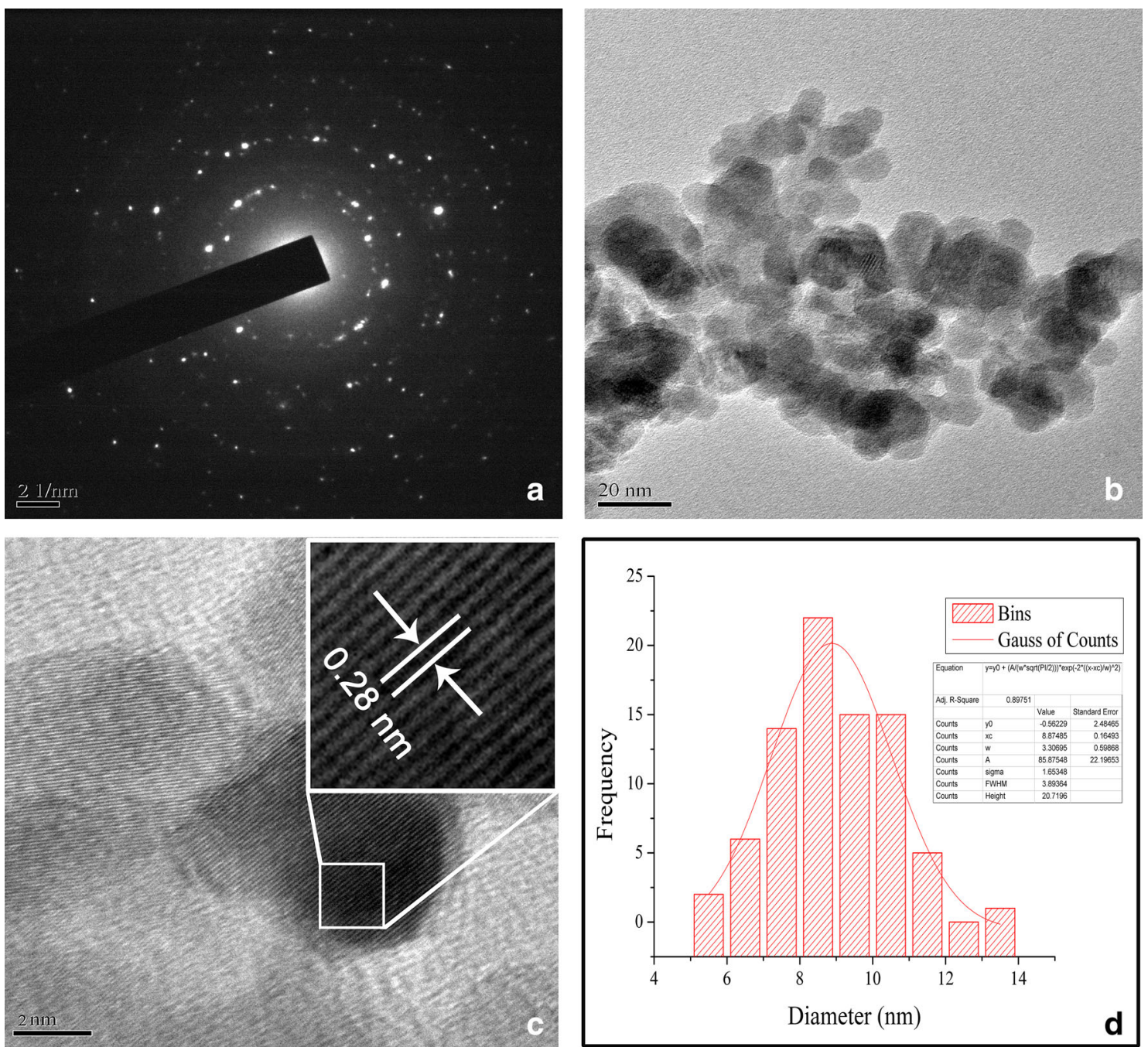

Fig. 5 a Selected area electron diffraction analysis of CuO NPs. b $20 \mathrm{~nm}$ resolution studies of synthesized CuO NPs. c Calculation of ' $d$ ' space with $2 \mathrm{~nm}$ resolution micrographs. d Particle size analysis with Gaussian fitting formula represents average size of the particles

used in the analysis of microscopic images. By this tool, synthesized nanoparticles were analyzed to know the size distribution of particles as well as the average size. Micrographs from TEM analysis showed $8.8 \mathrm{~nm}$ average size of the particles with 0.89 adjacent ' $R$ ' square value calculated by using the following Gauss fitting formula (Fig. 5d):

$\left(y=y 0+(A /(w \times \operatorname{sqrt}(P I / 2))) \times \exp \left(-2 \times((x-x c) / w)^{2}\right)\right.$.

Crystallographic toolbox (CrysTBox) is open source software, to implicate set of three automated tools to analyze crystallography of TEM-SAED micrographs. Regarding to diffractGUI and ringGUI tools are used to detect electron diffraction patterns of TEM-SAED micrographs. Another program cellViewer is used for the visualization of diffracted planes in 3D pattern. TEMSAED image of synthesized $\mathrm{CuO}$ NPs from stem bark was imported into diffractGUI tool. That automatically determines the zone of axis from a diffraction pattern to assign crystallographic indices to the diffracted atoms to measure inter planner angle of two atoms (Fig. 6a). The ringGUI tool automatically determines the crystallographic planes of synthesized material (Fig. 6b). The cellViewer, a visualization tool for depicting diffraction planes from diffractGUI displays, direct automatic lattice (cell view) (Fig. 6c) and reciprocal lattice (diffraction view) of the synthesized nanomaterials (Fig. 6d) (Klinger and Jager 2015). TEM-SAED pattern of synthesized nanoparticles was analyzed with this software displayed the planes of ' $h \mathrm{kl}$ ' integers were exactly matched with Bragg reflections of XRD results and JCPDS card file no. 80-1916. CrysTBox software is an astounding tool to correlate the characteristic crystallization pattern of XRD results with TEM-SAED pattern of synthesized $\mathrm{CuO}$ NPs. 

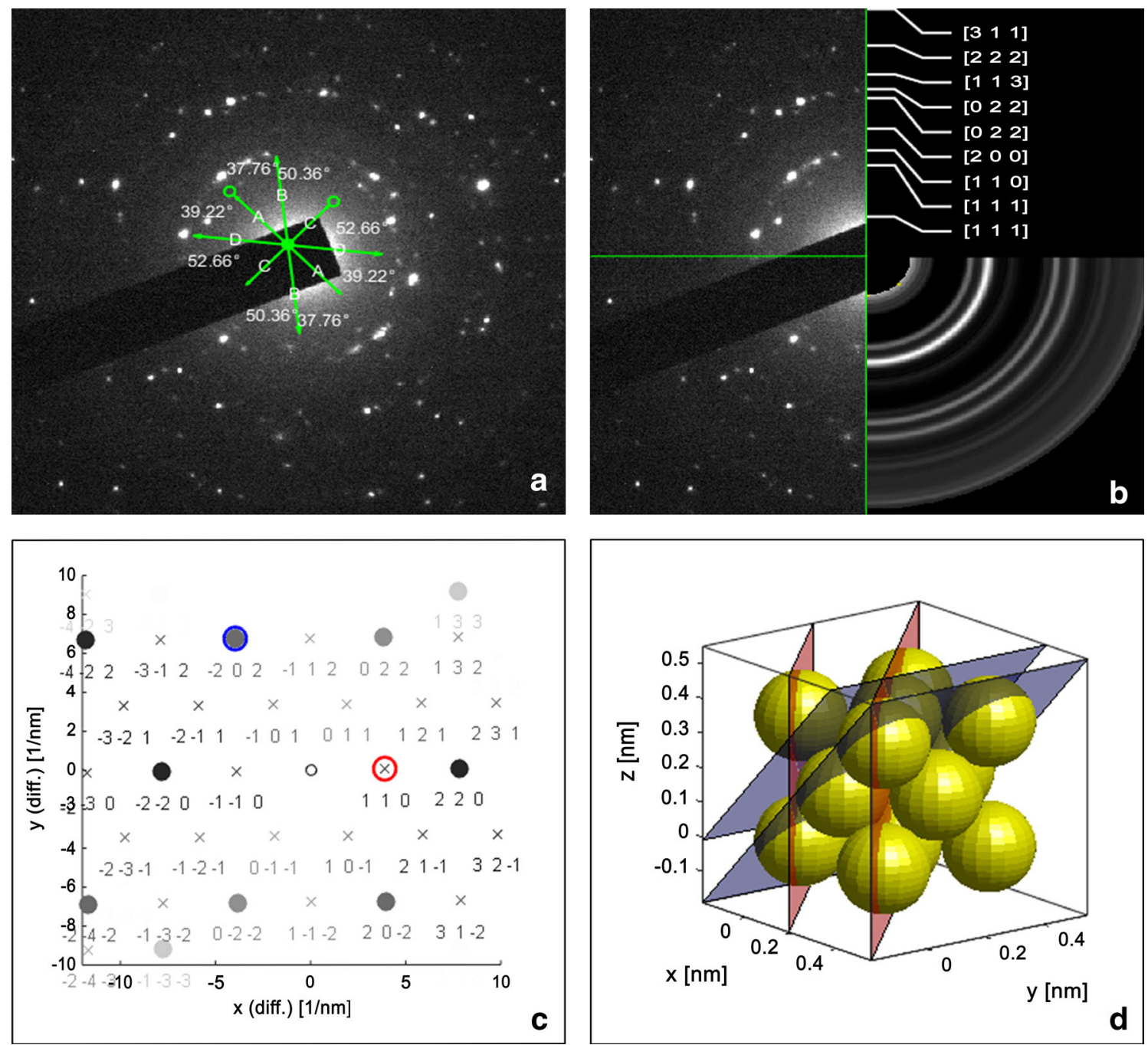

Fig. 6 a diffractGUI analysis of TEM-SAED pattern of $\mathrm{CuO}$ NPs. b ringGUI analysis of CuO NPs shows crystallographic planes. c Visualization of lattice planes in cell view. d Visualization of lattice planes in 3D diffraction view

\section{Antimicrobial activity}

Antimicrobial study of green synthesized $\mathrm{CuO}$ NPs has been shown noteworthy growth inhibitory results on different microorganisms. A highest zone of inhibition was observed in E. coli followed by $S$. aureus, these are gram negative and gram positive bacterial strains, respectively. Same type of highest growth inhibitory result was reported in E. coli by Meghana et al. (2015). Whereas in fungi the highest zone of inhibition was observed in T. harzianum (Figs. 7, 8). In this study, the zone of inhibition was observed less in fungi when compared with bacteria. Among the bacteria, a zone of inhibition was lesser in gram positive bacteria when compared with gram negative bacteria. This may arise due to fungal cell walls are made up of chitin, a fibrous substance comprising of polysaccharides having $N$-acetylglucosamine and a nitrogen group, which is more firm to allow the passage of nanoparticles from the outer layer of the cell wall to the inner layer. In case of bacteria, cell membranes are made up of peptidoglycan a polymer having sugars and amino acids, which is less firm and passage of nanoparticles is easy when compared with fungi. Among the bacterial strains passage of nanoparticle through the cell membrane is easy in the case of gram negative bacteria when compared to gram positive bacteria due to variation in manufacturing of cell membrane ( $\mathrm{Yu}-$ gandhar and Savithramma 2016a). Ren et al. (2009) elucidated that copper nanoparticles acts as inhibitory substances on microorganisms by the action of destroying enzymes of cell membranes. This might be possible by the small size and spherical shape of the particles have a high surface to volume ratio to interact with the cell membranes of microorganisms to exhibit the signs of growth inhibitory results (Agnihotri et al. 2014). Size, shape and agglomeration pattern of the nanoparticles depend on quantity-based presence of phytochemicals in medicinal plants. This might 

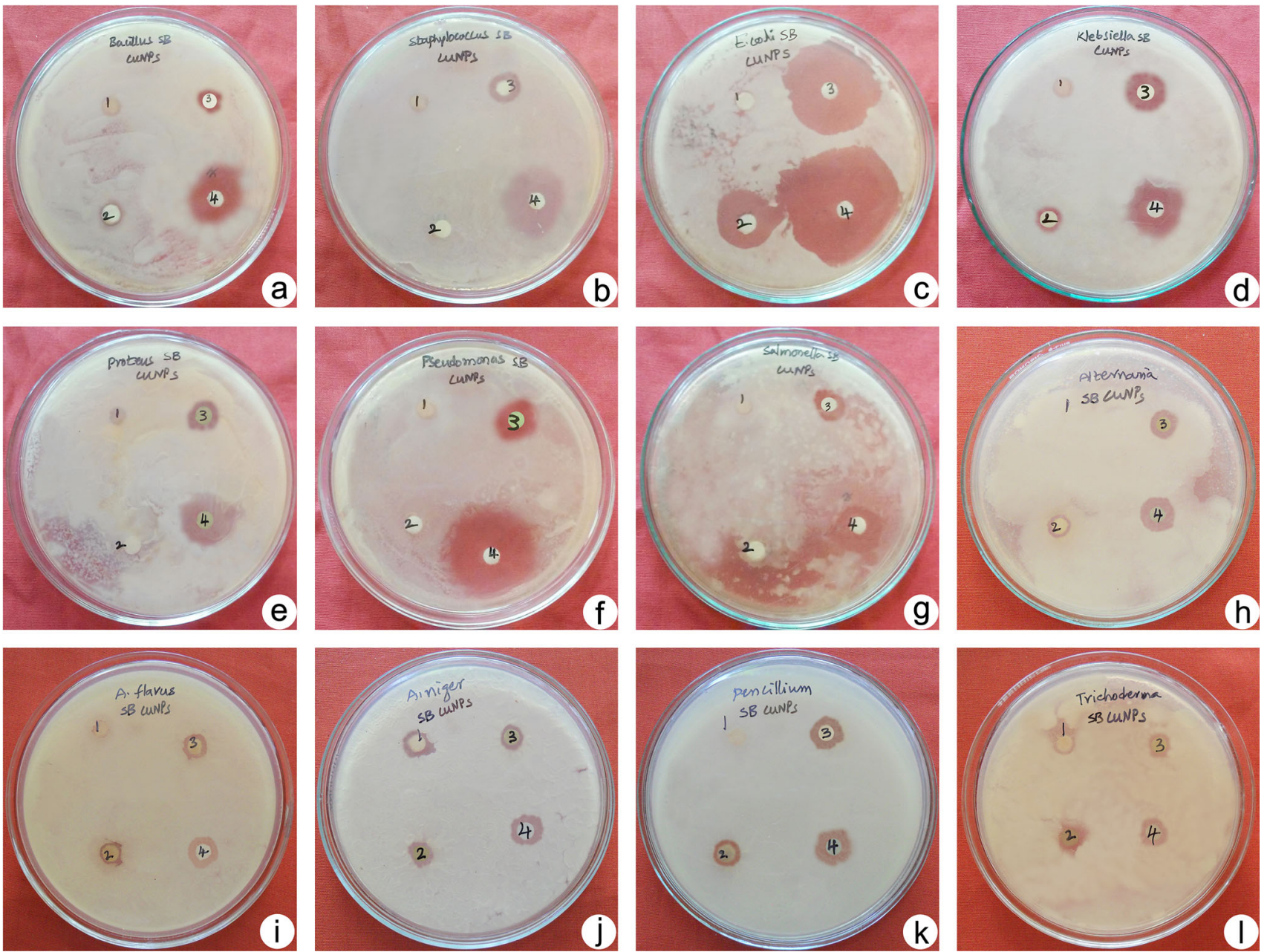

Fig. 7 Antimicrobial activity of synthesized CuO NPs. a B. subtilis, b $S$. aureus, c E. coli, d $K$. pneumoniae, e $P$. vulgaris, $\mathbf{f} P$. aeruginosa, g S. typhimurium, $\mathbf{h}$ A. solani, $\mathbf{i}$ A. flavus, $\mathbf{j}$ A. niger, $\mathbf{k} P$.

chrysogenum, I T. harzianum, 1 plant extract, $2 \mathrm{CuSO}_{4} \cdot 5 \mathrm{H}_{2} \mathrm{O}, 3$ $\mathrm{CuO}$ NPs, 4 Streptomycin/Fluconazole

Fig. 8 Antimicrobial activity of bioinspired green synthesis of $\mathrm{CuO}$ NPs from stem bark extract of S. alternifolium

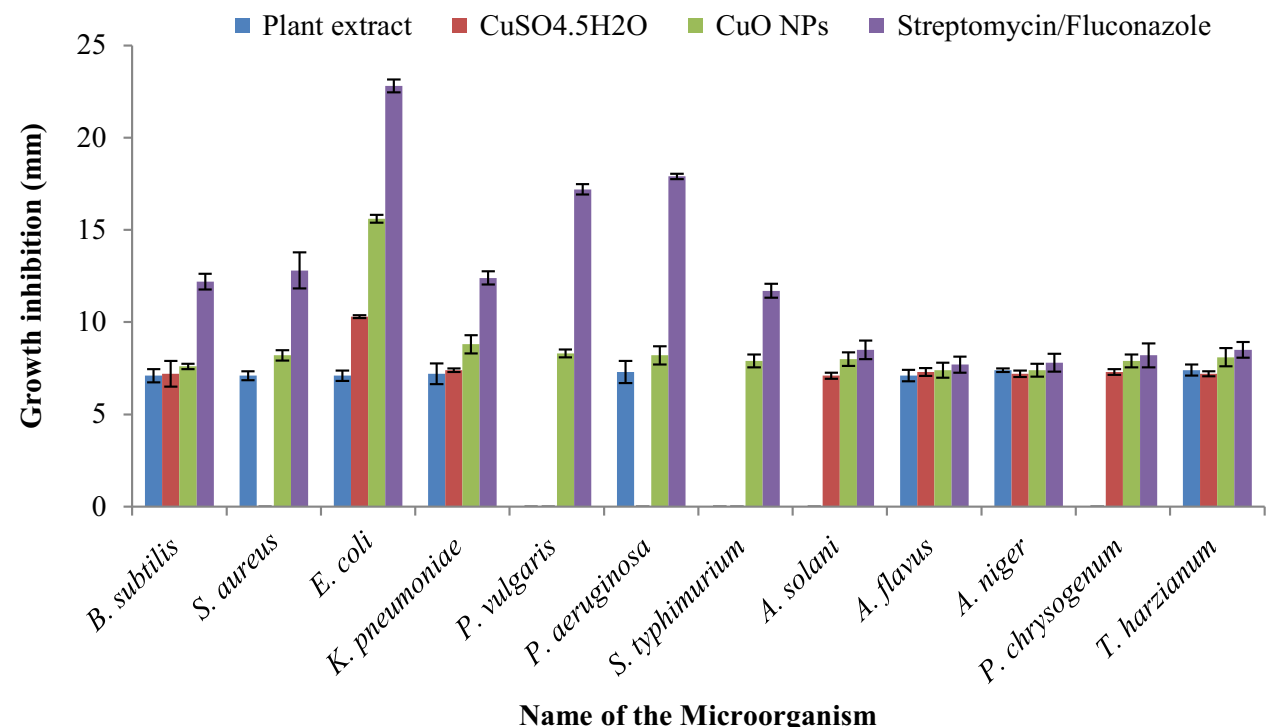



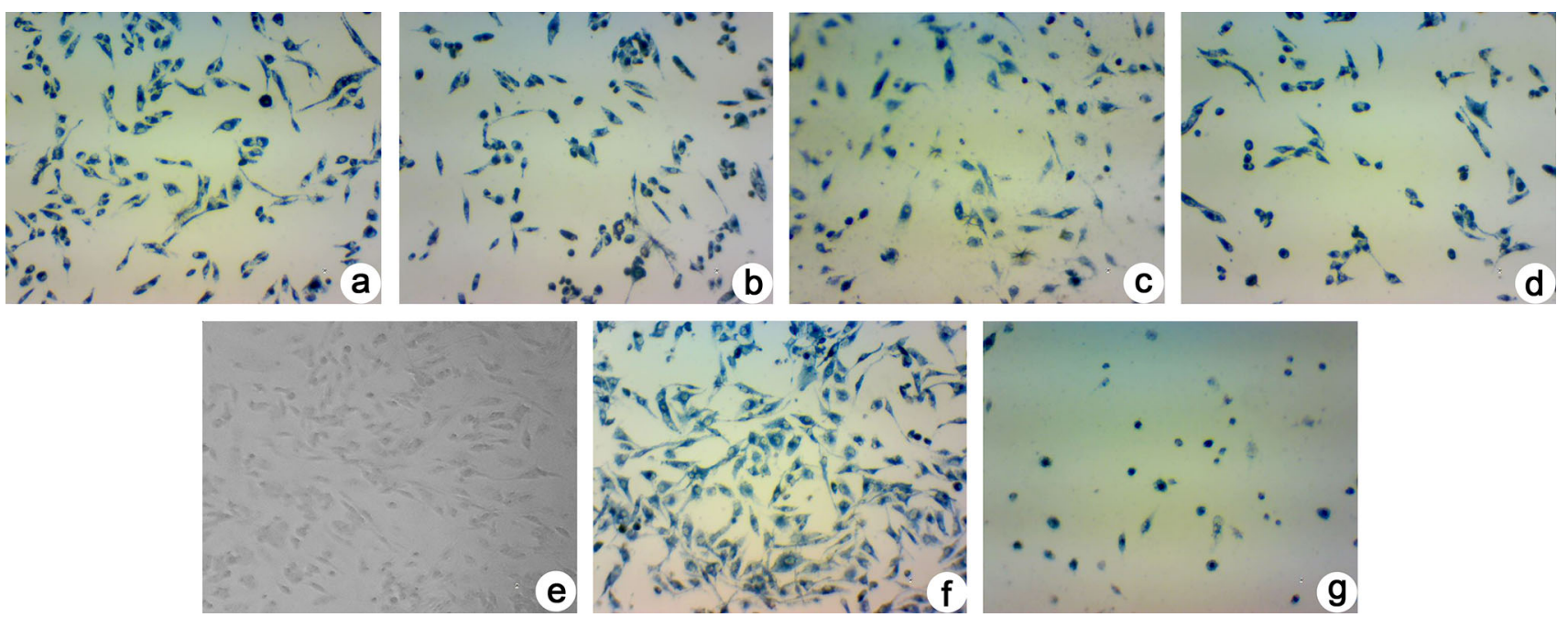

Fig. 9 Anticancer activity of synthesized CuO NPs. a $10 \mu \mathrm{g} / \mathrm{ml}$, b $25 \mu \mathrm{g} / \mathrm{ml}$, c $50 \mu \mathrm{g} / \mathrm{ml}$, d $100 \mu \mathrm{g} / \mathrm{ml}$, e untreated healthy cell lines, f DMSO $(0.1 \%)$ negative control, $\mathbf{g}$ doxorubicin $(1 \mu \mathrm{M})$ positive control

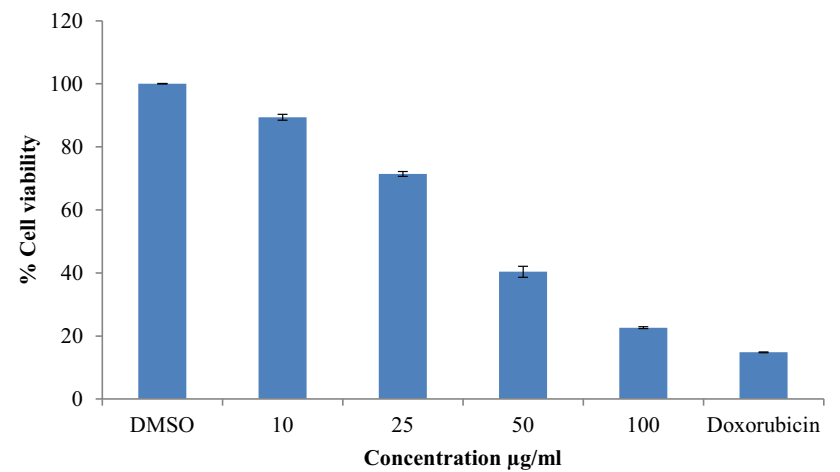

Fig. 10 Anticancer activity of bioinspired green synthesis of $\mathrm{CuO}$ NPs from stem bark extract of $S$. alternifolium

be useful in reducing, capping and stabilization of nanoparticles to narrow size with spherical shape (Saif et al. 2016). In this study it is found that CuO NPs synthesized from stem bark exhibit narrow size particles with spherical shape. This is because of plant S. alternifolium is a good source for different phytochemicals especially phenols and proteins (Yugandhar and Savithramma 2016b). These are possibly helpful in this study for capping and stabilization of nanoparticles. A similar kind of result was obtained from copper nanoparticles synthesized from A. indica leaf mediated particles, resulted with spherical shape with size range from 26 to $30 \mathrm{~nm}$ to exhibit excellent antimicrobial activity against different bacterial and fungal pathogens (Sivaraj et al. 2014).

\section{Anticancer activity}

The MDA-MB-231 human breast cancer cell lines were used for cytotoxicity analysis by reading formazan crystals formed by the reaction of mitochondrial dehydrogenase by MTT assay. At $48 \mathrm{~h}$ of time course incubation period, a significant abatement in cell viability was observed in the treated cell lines, while the concentration of CuO NPs was increased from $10,25,50$ and $100 \mu \mathrm{g} / \mathrm{ml}$. DMSO was used as a positive control to exhibit $100 \%$ of healthy proliferated cells (Figs. 9, $10)$. The $50 \mu \mathrm{g} / \mathrm{ml}$ concentration $\left(\mathrm{IC}_{50}\right.$ ) of CuO NPs may have the capability to reduce $50 \%$ of treated cell lines when compared with negative control. The cytotoxicity of nanoparticles may depend on the small size and spherical shape of the particles (Park et al.2011). In recent times, the $A$. indica leafmediated $\mathrm{CuO}$ NPs have the particle size ranging from 26 to $30 \mathrm{~nm}$, which showed strong cytotoxic activity against MCF7 breast cancer cell lines (Sivaraj et al. 2014). But, there is no report on $\mathrm{CuO}$ NPs synthesized from any medicinal plant to attribute anticancer activity against MDA-MB-231 breast cancer cell lines. From this study, the green synthesized $\mathrm{CuO}$ NPs from stem bark extract showed 5-13 nm size, spherical shaped particles, which exhibit strong cytotoxic activity against MDA-MB-231 cell lines.

\section{Conclusion}

The present study, reported a cost effective, eco-friendly, green approach method for production of $\mathrm{CuO}$ NPs from stem bark extract of $S$. alternifolium. Due to constraints with chemical- and physical-mediated methods, the green approach method is best opted technique to synthesize $\mathrm{CuO}$ NPs. The analytical tools like UV-vis spectroscopy and FT-IR studies revealed that the reduction of nanoparticle by ascorbic acid and the presence of phytochemicals like phenols and primary amines of proteins become helpful in capping and stabilization of particles. DLS and Zeta potential analysis revealed $2.6 \mathrm{~nm}$ average size and 
$-63.9 \mathrm{mV}$ of higher negative zeta potential value indicates greater stability of particles. The crystalline structure and $17.2 \mathrm{~nm}$ average size of the particles was revealed by XRD analysis. Microscopic analysis with TEM instrument showed spherical shaped particles with a size range from 5-13 nm. These particles were mostly settled in non-agglomerated and poly-dispersed condition. The software tools like ImageJ and CrystBox supports the calculation of average size and confirms the crystallographic nature of particles. The expository synergistic efficiency of CuO NPs showed growth inhibitory activity of microorganisms as well as MDA-MB-231 breast cancer cell lines. The presence of higher concentration of phenols and proteins in stem bark may be the reason behind for formation of narrow sized particles, bestowed to antimicrobial and anticancer activity. This study concludes that the plant $S$. alternifolium is an excellent green source for synthesis of copper oxide nanoparticles. This green approach method is very helpful in terms of endemic, endangered medicinal plant i.e., S. alternifolium. Here, the usage of plant material for synthesis is very limited and to produce greater quantities of nanoparticles in a non destructive way. This is the first report on bioinspired green synthesis of $\mathrm{CuO}$ NPs from the stem bark extract of S. alternifolium and too proved these nanoparticles as synergistic antimicrobial and anticancer agents. This study may pave a way for the futuristic synthesis of environmentally benign, cost effective $\mathrm{CuO}$ NPs from medicinal plants.

Acknowledgements The first author is highly grateful to UGC-BSR for providing meritorious fellowship and highly thankful to DSTPURSE, Sri Venkateswara University-Tirupati, SAIF-IIT-Madras, JNTU-Hyderabad for providing characterization facilities. Finally, greatly acknowledged to Prof. K. Suma Kiran, Department of English, Sri Venkateswara University for assisting grammatical and language corrections.

Open Access This article is distributed under the terms of the Creative Commons Attribution 4.0 International License (http:// creativecommons.org/licenses/by/4.0/), which permits unrestricted use, distribution, and reproduction in any medium, provided you give appropriate credit to the original author(s) and the source, provide a link to the Creative Commons license, and indicate if changes were made.

\section{References}

Agnihotri S, Mukherji S, Mukherji S (2014) Size-controlled silver nanoparticles synthesized over the range $5-100 \mathrm{~nm}$ using the same protocol and their antibacterial efficacy. RSC Adv 4:3974-3983. doi:10.1039/C3RA44507K

Angajala G, Pavan P, Subashini R (2014) One-step biofabrication of copper nanoparticles from Aegle marmelos correa aqueous leaf extract and evaluation of its anti-inflammatory and mosquito larvicidal efficacy. RSC Adv 4:51459-51470. doi:10.1039/ C4RA10003D
Baoshun W, Weiwei Z, Zhiyun Z, Renying L, Yulong W, Zhengguang $\mathrm{H}$ et al (2016) $\mathrm{Cu}_{2} \mathrm{O}$ hollow structures-microstructural evolution and photocatalytic properties. RSC Adv 6:103700-103706. doi:10.1039/C6RA22474A

Capek I (2004) Preparation of metal nanoparticles in water-in-oil (w/ o) microemulsions. Adv Colloid Interface Sci 110:49-74. doi:10. 1016/j.cis.2004.02.003

Cruickshank R (1986) Medical microbiology: a guide to diagnosis and control of infection. E\&S Livingston Livingston Ltd, Edinburghand, p 888

Ghidana AY, Al-Antarya TM, Awwadb AM (2016) Green synthesis of copper oxide nanoparticles using Punica granatum peels extract: effect on green peach Aphid. Environ Nano Monit Manag 6:95-98. doi:10.1016/j.enmm.2016.08.002

Ghosh S, More P, Nitnavre R, Jagtap S, Chippalkatti R, Derle A et al (2015) Antidiabetic and antioxidant properties of copper nanoparticles synthesized by medicinal plant Dioscorea bulbifera. J Nanomed Nanotechnol S6:1-9. doi:10.4172/2157-7439. S6-007

Jagadeesh M, Rashmi HK, Subba Rao Y, Sreenath Reddy A, Prathima B, Uma Maheswari Devi P et al (2013) Synthesis and spectroscopic characterization of 3,4-difluoroacetophenonethiosemicarbazone and its palladium(II) complex: evaluation of antimicrobial and antitumour activity. Spectrochim Acta A Mol Biomol Spectrosc 115:583-587. doi:10.1016/j.saa.2013.06.071

Kadirareddy RH, Vemuri SG, Palempalli UM (2016) Probiotic conjugated linoleic acid mediated apoptosis in breast cancer cells by downregulation of NFkB. Asian Pac J Cancer Prev 17:3395-3403

Kalyanaraman R, Yoo S, Krupashankara MS, Sudarshan TS, Dowding RJ (1998) Synthesis and consolidation of iron nanopwders. Nanostruct Mater 10:1379-1392. doi:10.2478/s11696-007-0014-7

Klinger M, Jager A (2015) Crystallographic tool box (CrysTBox): automated tools for transmission electron microscopists and crystallographers. J Appl Crystallogr 48:2012-2018. doi:10. 1107/S1600576715017252

Kumar CMK, Yugandhar P, Savithramma N (2016) Biological synthesis of silver nanoparticles from Adansonia digitata $\mathrm{L}$. fruit pulp extract, characterization, and its antimicrobial properties. J Intercult Ethnopharmacol 5:79-85. doi:10.5455/jice. 20160124113632

Kuppusamy P, Ilavenil S, Srigopalram S, Maniam GP, Yusoff MM, Govindan N et al (2017) Treating of palm oil mill effluent using Commelina nudiflora mediated copper nanoparticles as a novel bio-control agent. J Clean Prod 141:1023-1029. doi:10.1016/j. jclepro.2016.09.176

Meghana S, Kabra P, Chakraborty S, Padmavathy N (2015) Understanding the pathway of antibacterial activity of copper oxide nanoparticles. RSC Adv 5:12293-12299. doi:10.1039/ C4RA12163E

Padil VVT, Cernik M (2013) Green synthesis of copper oxide nanoparticles using gum karaya as a biotemplate and their antibacterial application. Int J Nanomedicine 8:889-898. doi:10. 2147/IJN.S40599

Park MV, Neigh AM, Vermeulen JP, de la Fonteyne LJ, Verharen HW, Briede JJ et al (2011) The effect of particle size on the cytotoxicity, inflammation, developmental toxicity and genotoxicity of silver nanoparticles. Biomaterials 32:9810-9817. doi:10. 1016/j.biomaterials.2011.08.085

Ren G, Hu D, Cheng EWC, Vargas-Reus MA, Reipd P, Allaker RP (2009) Characterisation of copper oxide nanoparticles for antimicrobial applications. Int $\mathrm{J}$ Antimicrob Agents 33:587-590. doi:10.1016/j.ijantimicag.2008.12.004

Saha D, Ved D, Ravikumar K, Haridasan K (2015) Syzygium alternifolium. The IUCN red list of threatened species 2015: e.T50130683A50131435 
Saif S, Tahir A, Asim T, Chen Y (2016) Plant mediated green synthesis of $\mathrm{CuO}$ nanoparticles: comparison of toxicity of engineered and plant mediated $\mathrm{CuO}$ nanoparticles towards Daphnia magna. Nanomaterials 6:1-15. doi:10.3390/ nano6110205

Sankar R, Maheswari R, Karthik S, Shivashangari KS, Ravikumar V (2014) Anticancer activity of Ficus religiosa engineered copper oxide nanoparticles. Mater Sci Eng C Mater Biol Appl 44:234-239. doi:10.1016/j.msec.2014.08.030

Savithramma N, Yugandhar P, Lingarao M (2014a) Ethnobotanical studies on Japali Hanuman Theertham-a sacred grove of Tirumala hills, Andhra Pradesh, India. J Pharm Sci Res 6:83-88

Savithramma N, Yugandhar P, Haribabu R, Sivaprasad K (2014b) Validation of indigenous knowledge of Yanadi Tribe and local villagers of Veyilingalakona - $\mathrm{a}$ sacred Grove of Andhra Pradesh, India. J Pharm Sci Res 6:382-388

Shende S, Ingle AP, Gade A, Rai M (2015) Green synthesis of copper nanoparticles by Citrus medica Linn. (Idilimbu) juice and its antimicrobial activity. World J Microbiol Biotechnol 31:865-873. doi:10.1007/s11274-015-1840-3

Sivaraj R, Rahman PK, Rajiv P, Narendhran S, Venckatesh R (2014) Biosynthesis and characterization of Acalypha indica mediated copper oxide nanoparticles and evaluation of its antimicrobial and anticancer activity. Spectrochim Acta A Mol Biomol Spectrosc. 14:255-258. doi:10.1016/j.saa.2014.03.027

Sudhakar C, Ramesh N, Vedavathy Nagaraju S, Sri Rama Murthy K (2012) Pharmacognostical studies on stem and fruit of Syzygium alternifolium (Wight) Walp - an endemic to South Eastern Ghats, India. Asian J Biochem Pharm Res 1:127-138

Tavakoli A, Sohrabi M, Kargari A (2007) A review of methods for synthesis of nanostructured metals with emphasis on iron compounds. Chem Pap 61:151-170. doi:10.2478/s11696-0070014-7

Tiwari M, Narayanan K, Thakar MB, Jagani HV, Venkata Rao J (2014) Biosynthesis and wound healing activity of copper nanoparticles. IET Nanobiotechnol 8:230-237. doi:10.1049/ietnbt.2013.0052

Umer A, Naveed S, Ramzan N (2012) Selection of a suitable method for the synthesis of copper nanoparticles. NANO Brief Rep Rev 7:1-18. doi:10.1142/S1793292012300058

Vijay Kumar PPN, Shameem U, Pratap K, Kalyani RL, Pammi SVN (2015) Green synthesis of copper oxide nanoparticles using Aloe vera leaf extract and its antibacterial activity against fish bacterial pathogens. BioNanoSci 5:135-139. doi:10.1007/ s12668-015-0171-z

Yugandhar P, Savithramma N (2016a) Biosynthesis, characterization and antimicrobial studies of green synthesized silver nanoparticles from fruit extract of Syzygium alternifolium (Wt.) Walp. an endemic, endangered medicinal tree taxon. Appl Nanosci 6:223-233. doi:10.1007/s13204-015-0428-4

Yugandhar P, Savithramma N (2016b) Spectroscopic and chromatographic exploration of different phytochemical and mineral contents from Syzygium alternifolim (Wt.) Walp. an endemic, endangered medicinal tree taxon. J App Pharm Sci 7:073-085. doi:10.7324/JAPS.2017.70110

Yugandhar P, Haribabu R, Savithramma N (2015) Synthesis, characterization and antimicrobial properties of green-synthesised silver nanoparticles from stem bark extract of Syzygium alternifolium (Wt.) Walp. 3 Biotech 5:1031-1039. doi:10.1007/ s13205-015-0307-4 